\title{
Daily performance at work: feeling recovered in the morning as a predictor of day-level job performance
}

\author{
CARMEN BINNEWIES*, SABINE SONNENTAG AND EVA J. MOJZA \\ University of Konstanz, Germany
}

\begin{abstract}
Summary This study examined the state of being recovered in the morning (i.e., feeling physically and mentally refreshed) as a predictor of daily job performance and daily compensatory effort at work. Ninety-nine employees from public service organizations completed a general survey and two daily surveys on pocket computers over the course of one workweek. Hierarchical linear modeling showed that being recovered in the morning was positively related to daily task performance, personal initiative, and organizational citizenship behavior and negatively related to daily compensatory effort at work. Relationships between the state of being recovered and day-specific job performance were moderated by job control. For persons with a high level of job control, the relationship between being recovered and daily performance was stronger.
\end{abstract}

\section{Introduction}

Individual job performance is a dynamic multidimensional construct that refers to employees behaviors at work that directly or indirectly support organizational goals (Motowidlo, Borman, \& Schmit, 1997). Although the dynamic nature of job performance has often been emphasized (Deadrick, Bennett, \& Russell, 1997; Ghiselli \& Haire, 1960), traditional research on job performance mainly focused on performance as a stable construct and analyzed between-person variability (Beal, Weiss, Barros, \& MacDermid, 2005). This line of research identified personal characteristics, such as cognitive ability and personality traits (e.g., conscientiousness) as predictors of individual job performance (Hunter \& Hunter, 1984; Mount \& Barrick, 1995). However, the dynamic nature of performance, and especially changes in performance over short periods of time within persons, has been largely neglected in earlier research (Beal et al., 2005).

In our study, we address this gap and examine predictors of daily job performance. Specifically, we link theory on dynamic performance (Beal et al., 2005) with the Conservation of Resources (COR) model (Hobfoll, 1989) and propose the state of being recovered, that is, having one's resources successfully replenished after a period of rest (Hobfoll \& Shirom, 2001), as a predictor of daily job

* Correspondence to: Carmen Binnewies, Department of Psychology, University of Konstanz, Postbox 42, D- 78457 Konstanz, Germany. E-mail: carmen.binnewies@uni-konstanz.de 
performance. Specifically, we hypothesize that individuals will show higher job performance on days when they are highly recovered in the morning than on days when they are poorly recovered.

Moreover, we examine job control as a moderator in the relationship between the state of being recovered and daily job performance. On the basis of research on situational strength (Mischel, 1977), we argue that high job control supports employees to capitalize on being highly recovered and enables employees to increase daily job performance.

Our study contributes to the literature in several ways. First, we examine the state of being recovered in the morning as a predictor of changes in day-to-day performance. Examining daily performance, we focus on different dimensions of daily performance, namely, daily task performance, daily proactive and helping behavior, and daily compensatory effort at work. Thereby, we enlarge our scarce knowledge of predictors of dynamic performance.

Second, we contribute to the literature on recovery by investigating if being highly recovered is related to performance-related outcomes. In particular, we used a within-person approach to examine the relationship between the state of being recovered and daily job performance and can, therefore, rule out interpretations based on differences between persons. In addition to examining task performance and personal initiative (PI) as outcome variables of the state of being recovered, we investigated two outcome variables that have not yet been studied in research on recovery: helping behavior as a core aspect of organizational citizenship behavior (OCB) (Organ, 1994) and compensatory effort spent at work. Compensatory effort refers to the amount of resources an individual has to spend in order to fulfill tasks and how easy it is to accomplish tasks (Hockey, 1993). Thus, compensatory effort is an indicator of performance-related costs (Hockey, 1997).

Third, we examine if job control - as an indicator of situational strength at work - plays a moderating role in the relationship between the state of being recovered and daily job performance. Job control describes the degree to which the workplace allows versus constrains employees in raising or decreasing their performance according to their state of being recovered. Therefore, by testing job control as a moderator, we investigate job control as a boundary condition for our theoretical assumptions on the state of being recovered and daily job performance.

\section{The Dynamic Nature of Daily Job Performance}

In their model of dynamic performance, Beal et al. (2005) provided a theoretical basis for examining changes in performance over time. In contrast to traditional performance models, a model of dynamic performance considers within-person differences to be substantial and meaningful (Beal et al., 2005). When examining dynamic performance, it is not an individual's general level of performance we are interested in, but an individual's variability in performance over time. Therefore, searching for predictors that explain within-person differences means identifying the conditions under which an individual is performing at best versus the conditions under which an individual is performing below his or her average. The main mechanism that Beal et al. (2005) proposed to be responsible for successful dynamic performance is resource allocation to the task. If an individual cannot allocate the maximum amount of resources to the task at hand, perhaps because he or she is struggling with fatigue, the individual cannot perform at his or her best. Resource allocation largely depends on the amount of an individual's available resources, especially on self-regulatory resources (Beal et al., 2005). Thus, replenishing and conserving resources is critical for upholding or increasing performance during a day or from day to day (Beal et al., 2005). 
Job performance is a multidimensional construct (Campbell, 1990; Motowidlo et al., 1997) and can on a general level be divided into task performance and contextual performance (Borman \& Motowidlo, 1993). Task performance refers to a person's contribution to organizational performance and is defined as behaviors "that are recognized by the formal reward systems and are part of the requirements as described in job descriptions" (Williams \& Anderson, 1991, p. 601). Contextual performance can be described as behavior that does not directly contribute to organizational performance but supports the organizational, social, and psychological environment (Borman \& Motowidlo, 1993). Contextual performance indirectly contributes to an organization's performance by facilitating task performance.

We propose that the basic assumptions on dynamic performance (Beal et al., 2005) apply to both task and contextual performance. Contextual performance should also show meaningful variation over time and the allocation of resources should also play a role in predicting high versus low levels of contextual performance over time.

In our study, we focused on two types of contextual behaviors, namely, PI (Frese, Kring, Soose, \& Zempel, 1996) and the helping dimension of OCB (Organ, 1994; Smith, Organ, \& Near, 1983). PI is one type of proactive behavior (Crant, 2000) and is defined as "a behavior syndrome resulting in an individual's taking an active and self-starting approach to work and going beyond what is formally required in a given job" (Frese et al., 1996, p. 38). In addition, helping is a core dimension of OCB (Organ, 1994; Smith et al., 1983). Behaviors subsumed under this concept are helping others who have problems (Podsakoff, MacKenzie, Paine, \& Bachrach, 2000) in building and preserving relationships and emphasizing interpersonal harmony (Van Dyne \& LePine, 1998). In sum, our study aims at investigating the dynamic nature of job performance, including different dimensions of daily job performance, namely, the qualitative aspect of task performance, and PI and OCB as two dimensions of contextual performance.

\section{The State of Being Recovered: An Outcome of the Recovery Process}

An individual's physical and mental resources are consumed and gradually depleted when accomplishing one's work and when coping with job-related stressors (Meijman \& Mulder, 1998). Recovery is the process that reverses the negative consequences of job demands and brings an individual back to his or her prestressor level of functioning (Craig \& Cooper, 1992). According to Hobfoll's COR model, individuals strive to gain, preserve, and protect their resources (Hobfoll, 1989; Hobfoll \& Shirom, 2001). Resources are defined as "those objects, personal characteristics, conditions, or energies that are valued by the individual or that serve as a means for attainment of these objects, personal characteristics, conditions, or energies" (Hobfoll, 1989, p. 516). During leisure time employees are no longer confronted with work-related demands, and thus leisure time provides the opportunity to prevent a further resource loss, to rebuild resources (e.g., energy, self-regulatory resources), and to gain additional resources (e.g., self-esteem) (Eden, 2001; Sonnentag, 2001). However, leisure time is not completely free of demands. Certain activities (e.g., housework, finishing work-related tasks) and experiences (e.g., daily hassles) during leisure time further draw on individuals' resources (Fritz \& Sonnentag, 2005; Sonnentag, 2001; Zijlstra \& Cropley, 2006). Other activities (e.g., social activities) and experiences (e.g., mentally switching off from work) enable individuals to prevent a further resource loss and to restore resources, such as energy or self-esteem (Fritz \& Sonnentag, 2005; Sonnentag \& Fritz, 2007; Zijlstra \& Cropley, 2006). Depending on the 
amount of resources that are built up versus further drained during leisure time, the employee is more or less recovered after this rest period (e.g., after the weekend or in the morning before the working day starts). In our study, we focused on the state of being recovered in the morning as an indicator of successful recovery resulting from activities or experiences pursued during previous leisure time. Being highly recovered implies feeling physically and mentally refreshed and to be full of energy (Sonnentag \& Kruel, 2006). When an individual indicates that he or she feels highly recovered in the morning, the individual has successfully restored and built up resources during the period of rest.

\section{The State of Being Recovered as a Predictor of Daily Job Performance}

The state of being recovered before going to work is the outcome of the previous recovery period, but simultaneously represents the starting point for acting and performing during the day. Being highly recovered in the morning implies that a high amount of resources is available for performing at work, whereas being poorly recovered implies that resources for performing at work are scarce or even lacking (Fritz \& Sonnentag, 2005). Such resources include energy, positive affect, self-esteem, or self-regulatory resources (Baumeister, Muraven, \& Tice, 2000; Hobfoll \& Shirom, 2001).

According to Beal et al. (2005, p. 1057), "performance during an episode is a joint function of resource level and resource allocation." Here, the core assumption is that an individual can achieve maximum performance when the maximum amount of resources is allocated to the task at hand. The more resources an individual has available at a specific time, the more resources can be allocated to the task, resulting into increased performance at this point in time. On days when an individual is highly recovered in the morning, he or she has more resources available that can be allocated to the task and thus an individual's job performance should increase. On the contrary, if an individual is poorly recovered in the morning, less resources are available that can be allocated to the task and an individual's job performance should decrease.

Self-regulatory resources should also be increased when an individual is highly recovered (Beal et al., 2005). Self-regulatory resources are necessary for monitoring and controlling cognitive processes, feelings, and behaviors (Muraven, Baumeister, \& Tice, 1999; Schmeichel \& Baumeister, 2004). In the context of dynamic performance, self-regulatory resources are needed for allocating attention and resources to the task at hand (Beal et al., 2005). Therefore, on days when an individual is highly recovered, he or she should possess more self-regulatory resources that facilitate resource allocation to the task and thereby foster daily job performance.

Taken together, we propose that on days when an individual is highly recovered in the morning, the individual shows increased performance at work. We hypothesize that task performance as well as contextual performance, that is, PI and OCB, will be higher when an individual is highly recovered.

Regarding empirical evidence from within-person analyses, Sonnentag (2003) showed that day-level recovery (i.e., being recovered, relaxed, and in a good mood) is positively related to daily PI. Furthermore, a recent study of Trougakos, Beal, Green and Weiss (2008) using a within-person approach in a sample of cheerleader instructors provided empirical evidence that recovery during work breaks is positively related to subsequent performance of affective delivery. Finally, we are not aware of any study, neither using a within- nor a between-person designs that examined the relationship between recovery and $\mathrm{OCB}$. In sum, we state the following hypotheses: 
Hypothesis 1: The state of being recovered in the morning will be positively related to daily task performance.

Hypothesis 2: The state of being recovered in the morning will be positively related to daily PI.

Hypothesis 3: The state of being recovered in the morning will be positively related to daily OCB.

When examining performance as an outcome variable, it is important to keep in mind that a specific level of performance can be achieved with different extents of effort expenditure. According to Hockey's (1993) compensatory control model, individuals try to compensate for a suboptimal state such as the lack of resources necessary for task fulfillment in order to prevent a performance breakdown. Spending more effort at work than usual (i.e., compensatory effort) is one prominent mechanism that individuals use to counteract a suboptimal state (Hockey, Wastell, \& Sauer, 1998; Hockey, 1993).

Compensatory effort differs from effort in terms of work motivation (Locke \& Latham, 2004). Whereas effort comprises duration, intensity, direction of behavior (Locke \& Latham, 1990), compensatory effort refers to how effortful or straining it is to accomplish tasks (Hockey, 1993). An individual can perceive task accomplishment very effortful, although the individual does not expend much effort in terms of duration or intensity.

On days when an individual is poorly recovered, he or she lacks resources for task accomplishment, and therefore has to spend compensatory effort to arrive at the same level of performance. The lack of self-regulatory resources should make it more difficult to allocate resources to the task and keep attention on the task (Beal et al., 2005). Thus, task accomplishment is more effortful and straining. On days when an individual is highly recovered, increased self-regulatory resources should facilitate resource allocation and attention to the task (Beal et al., 2005) and, therefore, should decrease the compensatory effort an individual has to spend at work. Therefore, we propose the following hypothesis:

Hypothesis 4: The state of being recovered in the morning will be negatively related to compensatory effort at work.

\section{The Moderating Role of Job Control as an Indicator of Situational Strength at Work}

An individual's ability to capitalize on the state of being highly recovered and to increase job performance by bringing in his or her resources at work may be contingent on the work environment. We argue that the relationship between the state of being recovered and daily performance is moderated by job control, as job control is an indicator of situational strength at work (Barrick \& Mount, 1993; Mischel, 1977).

Situations at work can be considered either strong or weak (Mischel, 1977). At work, a strong situation is characterized by many demands or pressures to conform and restricts an individual "in the range of behaviors that she or he may be both willing and able to exhibit" (Barrick \& Mount, 1993, 
p. 112). In contrast, a weak situation is marked by rather few demands or pressures and provides an individual with considerable freedom and discretion to determine which behaviors to undertake and how to execute them (Barrick \& Mount, 1993).

In organizational settings, job control has been proposed to be the most appropriate indicator of situational strength (Barrick \& Mount, 1993). Job control specifies how much influence a workplace offers over sequence, time frame, and content of one's work tasks (Jackson, Wall, Martin, \& Davids, 1993; Parker \& Wall, 1998). Accordingly, job control captures how much the situation prescribes and constrains (strong situation) or permits (weak situation) individual behavior at work. Thus, a high level of job control indicates a weak situation at work, whereas a low level of job control indicates a strong situation at work.

Similar to assumptions about the moderating role of situational strength in the relationship between personality and behavior (Barrick \& Mount, 1993; Beaty, Cleveland, \& Murphy, 2001), we propose that the strength of the situation - represented by job control - moderates the relationship between the state of being recovered and daily job performance. Feeling recovered in the morning should provide an individual with increased resources, that is, the capacity to show better task performance than usual and to go beyond what is formally required by engaging in PI or OCB. However, the situation at work may either constrain or enable an individual to take advantage of being highly recovered and increase daily job performance. Job control allows individuals to choose adequate strategies for handling their tasks and reaching their goals (Frese \& Zapf, 1994). Thus, job control determines an individual's possibilities to adjust performance.

When an individual is highly recovered and has a high level of job control, the individual can arrange tasks in such a way that the increased resources can be used most effectively. Accordingly, individuals with high job control can show increased performance when they are highly recovered. Furthermore, individuals with a high level of job control can deliberately decrease their performance if they are poorly recovered, for example, by delaying tasks or reducing the amount of work on a specific day. Thus, individuals can conserve their drained resources until they have the opportunity to restore their resources again (Hobfoll, 1989).

A low level of job control restricts an individual in his or her possibilities to arrange tasks in a way that allows the individual to take advantage of increased resources. Moreover, a low level of job control hinders an individual to deliberately decrease daily job performance when being poorly recovered. Because tasks have to be accomplished as prescribed, the individual cannot increase or decrease performance. Thus the workplace, specifically job control, restrains individuals' actions. Taken together, we propose the following hypotheses:

Hypothesis 5: Job control will moderate the relationship between the state of being recovered and daily task performance. The relationship will be stronger when job control is high.

Hypothesis 6: Job control will moderate the relationship between the state of being recovered and day-specific PI. The relationship will be stronger when job control is high.

Hypothesis 7: Job control will moderate the relationship between the state of being recovered and day-specific $O C B$. The relationship will be stronger when job control is high.

We propose an interaction effect of job control with the state of being recovered in the morning for all performance dimensions, specifically for task performance, for PI, and for OCB. We do not expect a moderator effect for compensatory effort at work, because compensatory effort instead represents performance-related costs and strain. On days when an individual is poorly recovered, accomplishing 
tasks should be perceived more effortful and straining by all employees, regardless if they have a high or low level of job control.

\section{Control Variables}

When examining the relationships between the state of being recovered with performance and compensatory effort at work, we have to take into account other possible confounding variables. On days when an individual is poorly recovered, the individual may perceive work as being more stressful because less resources are available to cope with job-related demands (Hobfoll, 1989; Lazarus \& Folkman, 1984). Due to decreased resources on such days, an individual may be more concerned that he or she does not have enough time to fulfill tasks or that needed material and information at work are insufficient. Furthermore, when being poorly recovered, an individual may experience more social stressors because he or she has less coping resources to tackle conflicts with supervisors or coworkers. As a result of these possibilities, we controlled for daily job stressors, specifically for day-specific time pressure, day-specific situational constraints, and day-specific social stressors at work.

In addition to day-level variables, person-level variables may impact daily performance and compensatory effort at work. An individual's general level of task performance, PI, OCB, or compensatory effort at work should affect the daily levels of these behaviors. Individuals differ in their general level of job performance (Beal et al., 2005). To account for these between-person differences, we controlled for the general level of the performance outcome and compensatory effort at work in the respective analyses.

Furthermore, age may be related to daily job performance. Older employees' cognitive resource can be different from younger employees since fluid intelligence declines with age and increased age is assumed to be associated with lower self-regulatory resources (Kanfer \& Ackerman, 2004). Although, age is also related to increased experience that may be related to a higher general level of job performance, decreased cognitive and self-regulatory resources may make it more difficult for older employees to allocate resources to tasks and thus may be related to decreased daily job performance. Therefore, we controlled for participants' age in our analyses.

\section{Organizational Context}

\section{Public Service Organizations in Germany and Switzerland}

Our study was conducted in 10 public service organizations located in the southern part of Germany and the northern part of Switzerland. Public service organizations in Germany and Switzerland are the administrative components of the state's executive power. We collected our data from public service organizations that are responsible for the administrative tasks of the local authority and commune. Public service organizations have to fulfill a broad range of tasks and provide different services employees work in a wide variety of jobs. Employees' main tasks range from directly supporting the local and financial administration, working in the social administration (e.g., as a social worker), providing services to citizens, working as technical specialists (e.g., as an engineer) to accomplishing supportive tasks (e.g., as a secretary). 


\section{Method}

\section{Overview}

Data were collected by a general survey and by daily surveys. Daily surveys were assessed by pocket computers over five consecutive working days. As this study is a part of a larger research project (Mojza, Peters, Sonnentag, \& Binnewies, 2007; Sonnentag, Binnewies, \& Mojza, 2008), we assessed a number of variables at three measurement occasions per day: (1) in the morning before participants went to work, (2) after work when participants arrived at home, and (3) in the evening before participants went to bed. Answering daily surveys started with responding to the survey after work on Monday and ended with responding to the bedtime survey on Friday. Therefore, we did not collect data on Monday morning. Consequently, this study focused on data assessed on four days in the morning and after work to examine the within-person relationships between the state of being recovered in the morning before going to work and performance during the working day. The sample used in this study is a subsample of all persons that participated in the larger research project.

\section{Sample}

Our participants came from 10 German and Swiss public service organizations. Site managers at public service organizations were approached and informed about the study. After managers expressed organization's consent to participate in the study, employees received an information letter that contained information about the study and a return form for registration. The study was announced to examine "recovery from work-related stress."

After participants agreed on participation, we sent them the general survey and scheduled a week for answering the daily surveys. We consigned pocket computers to the participants and explained the handling of the device, specifically how and when to answer the daily surveys. Furthermore, we set alarms on the pocket computers according to participants' preferences to remind them of answering daily surveys. To encourage participation, we promised organization-specific feedback and announced a lottery prize for all participants that completed the study.

A total of 106 persons agreed to participate in this study. Questionnaires were received from 104 persons corresponding to a questionnaire response rate of 98.1 per cent. All 106 persons received a pocket computer and provided daily survey data. Due to technical problems, four persons could not answer daily surveys from Day 3 to Day 5 and were completely excluded from analyses. Pocket computers recorded the time when participants answered daily surveys. Thus, we were able to check if daily surveys were filled in at the right time, that is, at a time that corresponded to our instructions for answering daily surveys in the morning (i.e., before leaving home to go to work) and after work (i.e., after returning home from work). In total, nine morning surveys ( 2.3 per cent of all possible measurement points) and nine bedtime surveys ( 2.3 per cent of all possible measurement points) were answered at a wrong time and were therefore excluded from analyses. ${ }^{1}$

After excluding data answered at wrong times, response rates for correctly answered survey data for morning surveys on the four days ranged from 84.9 to 96.2 per cent $($ mean $=91.7)$, and for after-work surveys from 80.2 to 98.1 per cent $($ mean $=90.6)$. One more person was excluded because this person missed daily surveys or answered them at wrong times every day. In total, our analyses are based on daily survey and questionnaire data of 99 persons, including 359 measurement occasions corresponding to 90.7 per cent of all possible 396 measurement occasions.

\footnotetext{
${ }^{1}$ We tested whether participants whose daily survey data were partly excluded differed from the rest of participants. Furthermore, for participants with excluded data, we tested whether day-level variables differed between days when daily surveys were answered at a wrong time and days when daily surveys were answered according to our study instructions. Results showed no differences suggesting that excluding data was not selective.
} 
Of the 99 persons included in analyses, 67.7 per cent were female and 32.3 per cent were male. Mean age was 38.7 years $(S D=10.2)$, ranging from 17 to 61 years. On average, participants had 15.3 years of professional experience $(\mathrm{SD}=9.5)$ and 10.3 years of professional experience in their current organizations $(\mathrm{SD}=8.9)$. Participants held a variety of public service jobs. The majority of our sample, 50.1 per cent had primarily administrative jobs (e.g., civil servants in the local and financial administration of small towns and villages), 20.2 per cent had jobs in the field of social administration and service (e.g., social workers), 15.2 per cent had superior administrative jobs (e.g., chief officers of larger administrative units), 5.1 per cent had jobs as support staff (e.g., secretaries), 4.0 per cent had professional jobs in technical fields (e.g., geodesists), and the remaining 5.1 per cent of the sample worked in a variety of other jobs. In terms of educational background, 52.2 per cent held a degree from university, 37.4 per cent had completed a 2- to3-year professional training, 5.1 per cent had completed a 2- to 3-year professional training and had obtained an additional professional degree, and 4.0 per cent held no professional degree. About one third (30.3 per cent) had a leadership position.

\section{Measures}

Data were assessed by a paper-based general survey and by daily surveys administered on pocket computers. All items were in German and had to be answered on a five-point Likert scale ranging from $1=$ not true at all to $5=$ very true (except for demographic data). Items from scales that were originally developed in English were translated into German by the first author and translated back to English by an interpreter to ensure that content and meaning remained unchanged during the translation process.

\section{General survey data}

After registration participants received the general survey and were instructed to complete this general survey before answering daily surveys. The general survey assessed job control, measures of the general level of job performance and of compensatory effort at work, and participants' age.

General level of job control was assessed with a scale developed by Semmer (1984) and Zapf (1993). This scale is widely used in German-speaking countries and has been extensively validated (Semmer, Zapf, \& Dunckel, 1999; Semmer, Zapf, \& Greif, 1996). The scale measures method control and consists of five items (sample item: "How much can you influence the way how you accomplish your tasks?"). Cronbach's alpha was .72.

General level of task performance was measured by three items from the performance scale of Roe, Zinovieva, Dienes, and Horn (2000), which assesses how well a person accomplishes his or her tasks at work (sample item: "Compared to the standards I usually get good results from my work”). Cronbach's alpha was .77.

General level of personal initiative was measured with a seven-item scale capturing a person's general tendency to show PI at work (Frese, Fay, Hilburger, Leng, \& Tag, 1997, sample item: "I actively attack problems"). Cronbach's alpha was .84 .

General level of organizational citizenship behavior. Originally we wanted to assess the general level of OCB and day-level OCB with the OCBI scale of Williams and Anderson (1991). However, some items of the OCBI scale of Williams and Anderson (1991) were not suitable for our day-level measure of OCB because they capture OCB behaviors that are not likely to occur every day (e.g., orienting new people or helping others who have been absent for a while). Therefore, we complemented suitable items of the OCBI scale of Williams and Anderson (1991) with suitable items of the OCB helping scale of Staufenbiel and Hartz (2000). The scale of Staufenbiel and Hartz (2000) was developed and derived on the basis of OCB concepts and scales suggested by Smith et al. (1983), Organ (1997), and Podsakoff et al. (2000). Our final five-item scale covers the helping dimension of 
OCB. All items measure a person's tendency to help coworkers and to maintain a pleasant working climate (sample items: "I pass along information to co-workers," "I take time to listen to co-workers' problems and worries"). Cronbach's alpha was .68.

General level of compensatory effort at work was measured by three items developed for this study. The scale measures how exhausting and straining it is in general to perform at work. It therefore assesses how much compensatory effort a person has to expend in general to achieve a certain level of performance. Our measure of compensatory effort differs from measures of effort that assess the duration or intensity of behavior. The three items were "It needs much energy to work on my tasks," "I am doing my work with ease" (reverse coded), and "I have to expend much effort in order to accomplish my tasks." Cronbach's alpha was .81.

We conducted confirmatory factor analyses (CFAs) to examine if the three performance measures and compensatory effort were best represented by a four-factor model. Specifically, we tested the four-factor model against a one-factor model and against various three- and two-factor models. Results from CFAs for the four-factor model showed a satisfactory fit $\left(\chi^{2}=164.3, \mathrm{df}=129, p=.02\right.$, RMSEA $=0.053, \mathrm{CFI}=0.95, \mathrm{NNFI}=0.93$ ). The four-factor model fit the data better than the one-factor model $\left(\Delta \chi^{2}=250.8, \Delta \mathrm{df}=6, p<.001\right)$, than different two-factor models $\left(\Delta \chi^{2} \geq 103.4\right.$, $\mathrm{df}=5, p<.001)$, and three-factor models $\left(\Delta \chi^{2} \geq 38.8, \Delta \mathrm{df}=3, p<.001\right)$.

\section{Daily survey data}

Daily surveys assessed the state of being recovered, daily job performance, daily compensatory effort, and daily stressors at work. The state of being recovered in the morning was measured in the morning, before participants went to work. All other daily survey measures were assessed after work.

State of being recovered in the morning was measured by a four-item scale (Sonnentag \& Kruel, 2006). The scale refers to how recovered a person feels in the morning. The four items were as follows: "This morning I feel well rested," "This morning I feel physically refreshed," "This morning I feel mentally refreshed," and "This morning I am filled with new energy." Cronbach's alpha ranged from .88 to .93 (mean $=.92$ ) over the four days.

Day-level task performance was measured with three items adapted from the performance scale of Roe et al. (2000). Our measure assessed how well an individual accomplished his or her work task on the specific day (sample item: "Compared to the standards I got good results from my work today"). Cronbach's alpha ranged between .67 and .81 (mean $=.77$ ).

Day-level personal initiative was assessed with seven adapted items from the scale of Frese et al. (1997), which measures the degree of PI shown at work during the specific day (sample item: "Today, I actively attacked problems"). Cronbach's alpha ranged from .85 to .88 (mean $=.86$ ).

Day-level organizational citizenship behavior was assessed with five adapted items from the OCBI scale of Williams and Anderson (1991) and from the OCB helping scale of Staufenbiel and Hartz (2000). All items were adapted to measure the day-specific level of OCB, that is, the degree a person helped and encouraged coworkers and maintained a pleasant working climate during the specific day (sample items: "Today, I passed along information to co-workers," "Today, I took time to listen to co-workers problems and worries"). Cronbach's alpha ranged between .71 and .81 (mean =.78.).

Day-level compensatory effort at work was measured by three items developed for this study. The scale measures how exhausting and straining it was on the specific day to perform at work. Thus, it assessed how much compensatory effort a person had to expend during the day to achieve a certain level of performance. The three items were as follows: "Today, it needed much energy to work on my tasks," "Today, I did my work with ease" (reverse coded), "Today, I had to expend much effort in order to accomplish my tasks." Cronbach's alpha ranged between .78 and .88 (mean $=.85$ ).

We conducted CFAs to confirm that the three daily performance measures and daily compensatory effort were best represented by a four-factor model. As suggested by Bolger, Davis, and Rafaeli (2003), 
we conducted CFAs with day-level performance data that was centered around the person mean. Results from CFAs for the four-factor model showed a satisfactory fit $\left(\chi^{2}=383.99, \mathrm{df}=129, p<.001\right.$, $\mathrm{RMSEA}=0.065, \mathrm{CFI}=0.94, \mathrm{NNFI}=0.93)$. The four-factor model fit the data better than the one-factor model $\left(\Delta \chi^{2}=250.8, \Delta \mathrm{df}=6, p<.001\right)$, than different two-factor models $\left(\Delta \chi^{2} \geq 404.8\right.$, $\Delta \mathrm{df}=5, p<.001)$, and three-factor models $\left(\Delta \chi^{2} \geq 160.8, \Delta \mathrm{df}=3, p<.001\right)$.

Daily job stressors. To assess daily job stressors as control variables, we measured three organizational stressors that presumably vary between days, particularly day-level situational constraints, day-level time pressure, and day-level social stressors. We used shortened scales of the situational constraints and time pressure measures developed by Semmer (1984) and Zapf (1993) and a shortened scale of the social stressors measure developed by Frese and Zapf (1987). Situational constraints were assessed with three items (sample item: "Today, I had to work with materials and information that were incomplete and out-dated"), time pressure was assessed with three items (sample item: "Today, I was required to work fast at my work"), and social stressors were assessed with six items (sample item: "Today, some colleagues were unpleasant co-workers"). Cronbach's alpha on the five days ranged between .76 and .81 for situational constraints (mean $=.79$ ), between .81 and .85 for day-level time pressure $($ mean $=.83)$, and between .61 and .75 for social stressors $(\operatorname{mean}=.69)$.

\section{Data analyses}

We had data from each person at two levels: at the person level (Level 2) and at the day level (Level 1), with day-level data nested within persons. Job control, the general level of performance variables, and compensatory effort at work and age constituted Level 2 data. The state of being recovered in the morning, daily job stressors, and day-level measures of performance variables and compensatory effort at work constituted Level 1 data. Hierarchical linear modeling was used to analyze our data because it accounts for the dependence of observations at the lower level (Bryk \& Raudenbush, 1992; Snijders \& Bosker, 1999). We used the MLwiN software (Rasbash et al., 2000) for data analysis. Person-level predictor variables were centered around the grand mean and day-level predictor variables were centered around the respective person mean. We centered variables at Level 1 around the respective person mean because we wanted to eliminate between-person variance in order to attribute effects of Level 1 variables to within-person effects and to rule out interpretations based on between-person differences. Thus, we were not interested if the absolute level of being recovered in the morning is related to day-specific performance, but if an increased or decreased state of being recovered in the morning within a person (i.e., compared to the respective mean of this individual) is related to an increase or decrease in day-specific performance.

\section{Results}

Means, standard deviations, and zero-order correlations are displayed in Table 1. For calculating the correlations between day-level and person-level variables, day-level variables were averaged across the four days. Before testing hypotheses, we examined the variability of dependent variables across the four days. Information about the variation of dependent variables can be seen from the null models (see Tables 2-5). For day-level task performance, the variance at Level 2 was 0.216 and at Level 1 it was 0.458 . Thus, the total variance was 0.674 , and 68 per cent $(0.458)$ of the total variance was attributable to within-person variation, whereas 32 per cent $(0.216)$ was attributable to between-person variation. 


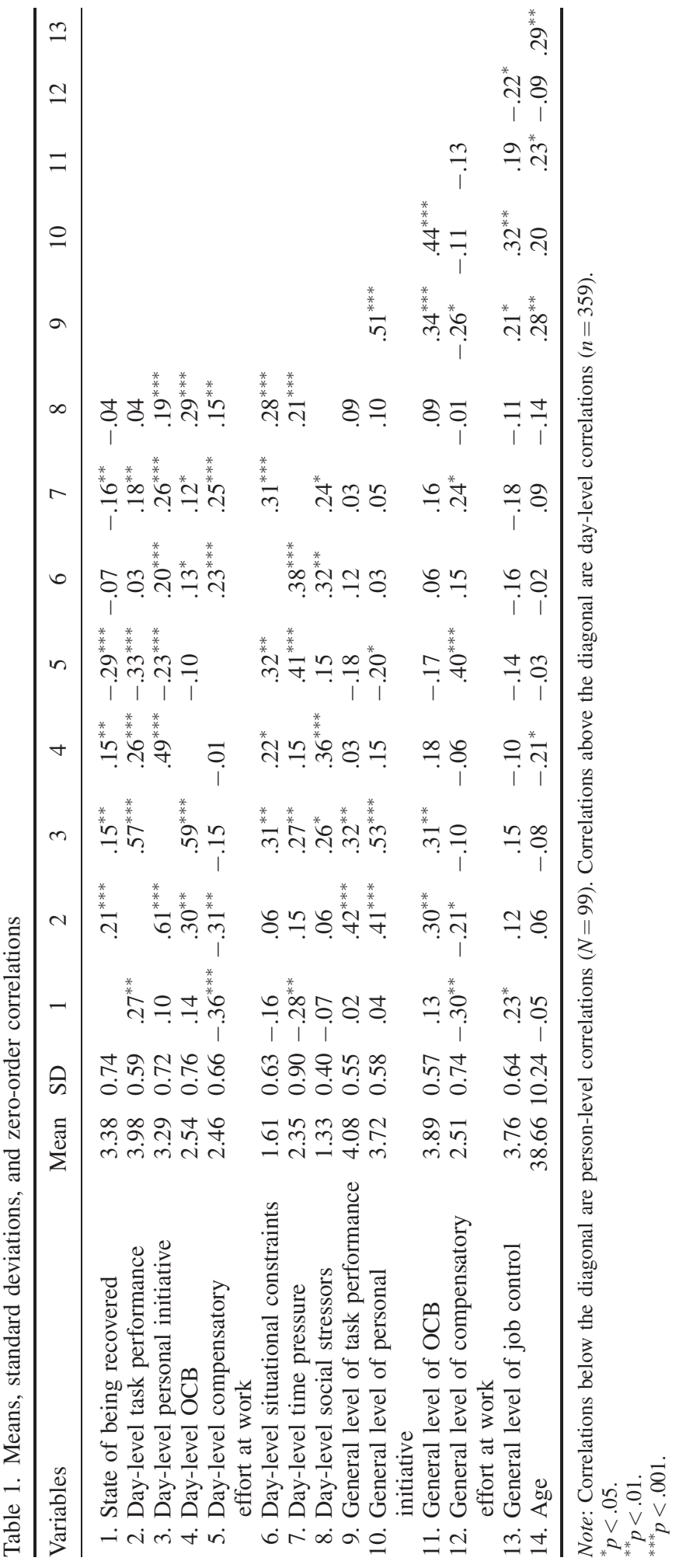


For day-level PI, 56 per cent of the variance was attributable to within-person variation, for day-level OCB 50 per cent, and 76 per cent for day-level compensatory effort at work. These results show substantive variation both between and within persons.

\section{Test of hypotheses}

To test our hypotheses, we conducted multilevel analyses for each dependent variable (i.e., day-level task performance, day-level PI, day-level OCB, and day-level compensatory effort). For each of these variables, we compared four different models: null model, Model 1, Model 2, and Model 3. In the null model, the intercept was the only predictor. In Model 1, control variables at the person level were entered, specifically age and the general level of the respective criterion variable (e.g., general level of task performance). In addition, we entered job control into Model 1. In Model 2, daily job stressors were entered as control variables, specifically day-specific situational constraints, day-specific time pressure, and day-specific social stressors. In Model 3, we included the state of being recovered in the morning as the predictor to test Hypotheses 1-4. Furthermore, we specified a fourth model for task performance, PI, and OCB, in which we entered the interaction term of job control and the state of being recovered in the morning to test for the interaction effects assumed in Hypotheses 5-7.

Table 2 shows all models for day-level task performance, including estimates, standard errors, and $t$-values for all predictor variables and the likelihood values for all models, and differences between the likelihood values of models to be compared. Model 1 showed a significant improvement over the null model $(\Delta-2 \times \log =20.792, \Delta \mathrm{df}=4, p<.001)$. The general level of task performance was the only significant predictor. Model 2 showed an additional improvement over Model $1(\Delta-2 \times \log =17.418$, $\Delta \mathrm{df}=3, p<.001)$. Day-level time pressure positively predicted day-level task performance. Model 3 showed further improvement $(\Delta-2 \times \log =3.932, \Delta \mathrm{df}=1, p<.05)$ and the state of being recovered in the morning was found to be a significant positive predictor of day-level task performance, indicating support for Hypothesis 1. Moreover, Model 4 showed a further improvement over Model 3 $(\Delta-2 \times \log =4.669, \Delta \mathrm{df}=1, p<.05)$ with the interaction term significantly predicting day-level task performance. According to the procedure proposed by Aiken and West (1991), we divided our sample into two subgroups including persons with low (i.e., below the median) versus high (i.e., above the median) job control. We performed multilevel analyses for both subgroups to test the simple slopes of the state of being recovered on daily job performance. For persons with high job control, the state of being recovery was positively related to day-level task performance $(\gamma=0.299, \mathrm{SE}=0.098, t=3.05$, $p<.01$ ), whereas for persons with low job control, the state of being recovery was unrelated to day-level task performance $(\gamma=-0.057, \mathrm{SE}=0.083, t=-0.69$, ns). Consequently, Hypothesis 5 was supported. Figure 1 displays the interaction effect.

Results for day-level PI can be seen in Table 3. Model 1 showed a significant improvement over the null model $(\Delta-2 \times \log =38.924, \Delta \mathrm{df}=4, p<.001)$. The general level of PI was a positive predictor and age was a negative predictor of day-level PI. Model 2 showed an additional improvement over Model $1(\Delta-2 \times \log =18.305, \Delta \mathrm{df}=3, p<.001)$. Day-level time pressure positively predicted day-level PI. Model 3 showed further improvement over Model $2(\Delta-2 \times \log =12.007, \Delta \mathrm{df}=1$, $p<.001)$ and the state of being recovered in the morning was found to be a significant positive predictor of day-level PI. Therefore, Hypothesis 2 was confirmed. Moreover, Model 4 showed a further improvement over Model $3(\Delta-2 \times \log =11.775, \Delta \mathrm{df}=1, p<.001)$ and the interaction term significantly predicted day-level PI. For persons with high job control, the state of being recovered in the morning was positively related to day-level PI $(\gamma=0.501, \mathrm{SE}=0.106, t=4.73, p<.001)$, whereas for persons with low job control, the state of being recovered was unrelated to day-level PI $(\gamma=0.011$, 


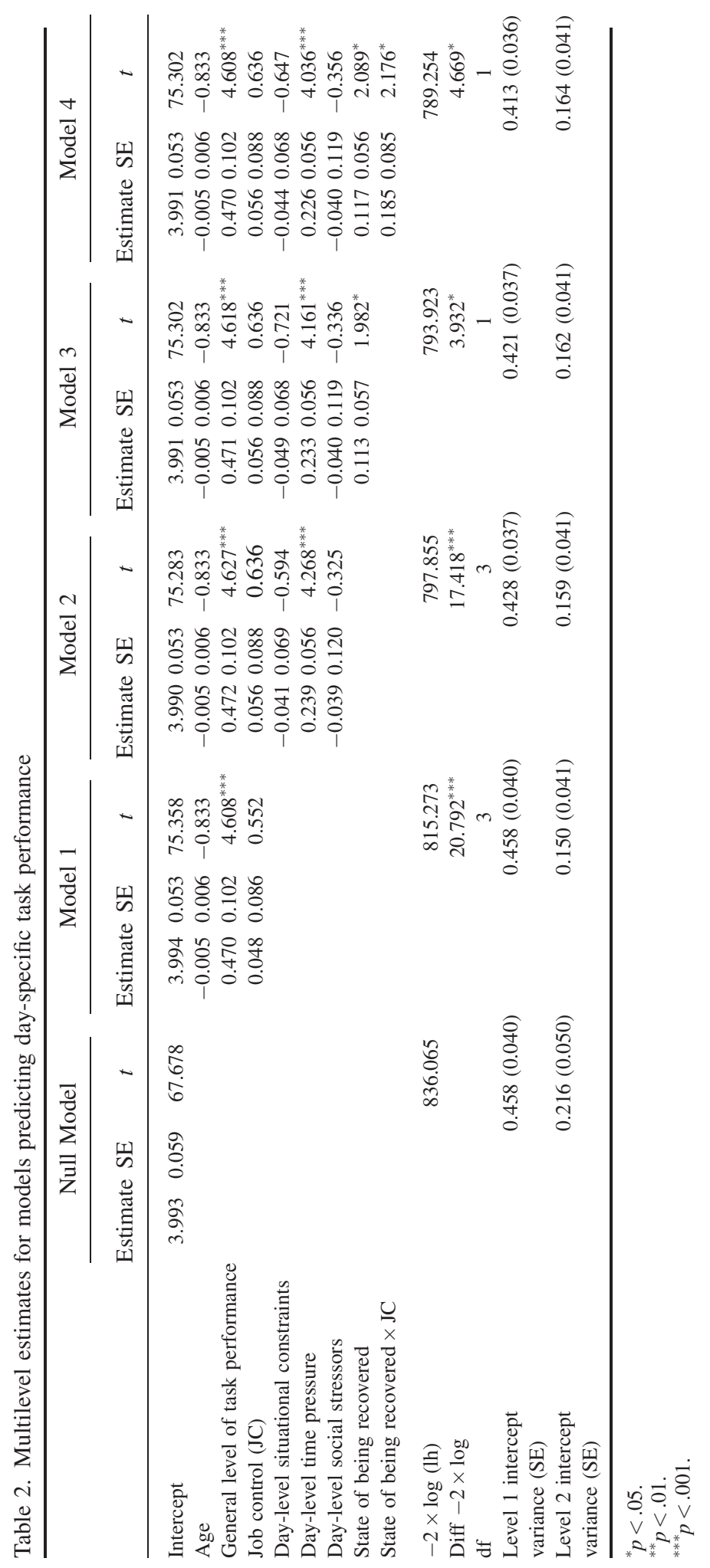




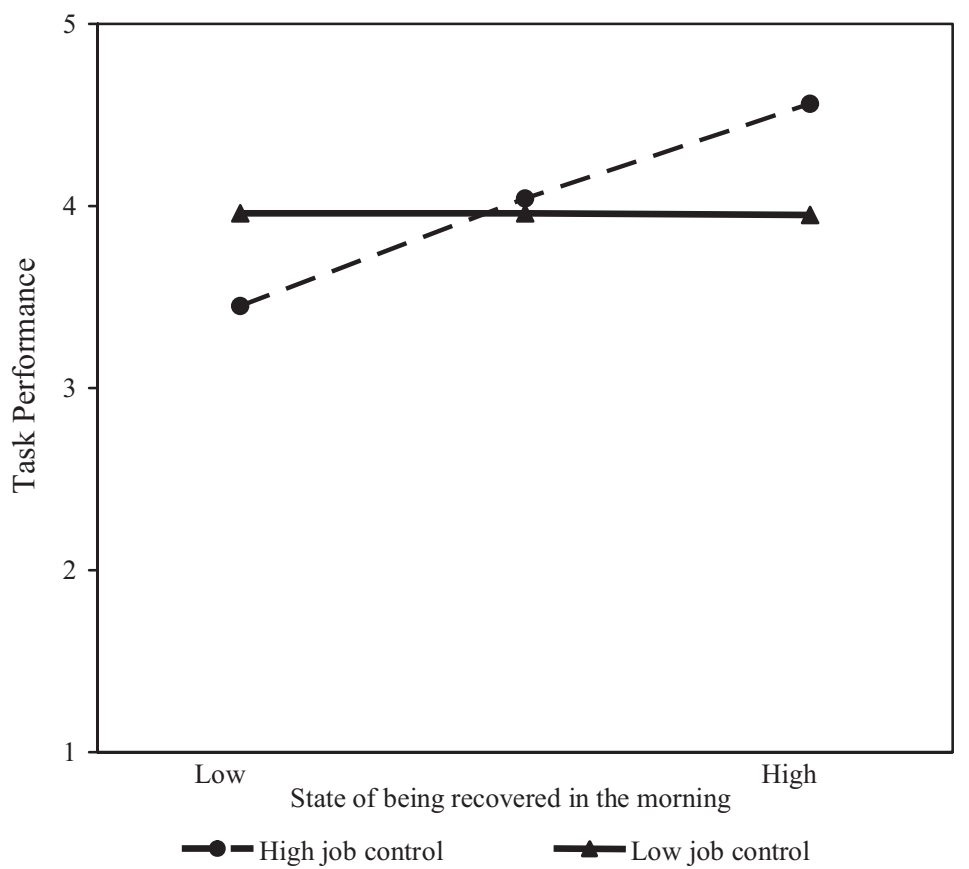

Figure 1. The interaction effect of the state of being recovered in the morning and job control on task performance

$\mathrm{SE}=0.069, t=0.16, \mathrm{~ns})$. Consequently, Hypothesis 6 was supported. The interaction effect is displayed in Figure 2.

Table 4 shows the results for day-level OCB. Model 1 showed a significant improvement over the null model $(\Delta-2 \times \log =10.093, \Delta \mathrm{df}=4, p<.05)$, and the general level of OCB was a positive predictor and age a negative predictor of day-level OCB. Model 2 showed an additional improvement over Model $1(\Delta-2 \times \log =11.201, \Delta \mathrm{df}=3, p<.05)$. Day-level social stressors positively predicted day-level OCB. Model 3 showed a further improvement over Model $2(\Delta-2 \times \log =5.549, \Delta \mathrm{df}=1$, $p<.05)$ and the state of being recovered in the morning was found to be a significant positive predictor of day-level OCB. Therefore, Hypothesis 3 was confirmed. Moreover, Model 4 showed a further improvement over Model $3(\Delta-2 \times \log =8.025, \Delta \mathrm{df}=1, p<.01)$ and the interaction term significantly predicted day-level OCB. For persons with high job control, the state of being recovered in the morning was positively related to day-level OCB $(\gamma=0.296, \mathrm{SE}=0.099, t=2.99, p<.01)$, whereas for persons with low job control, the state of being recovered was unrelated to day-level OCB $(\gamma=-0.008, \mathrm{SE}=0.075, t=-0.11, \mathrm{~ns})$. Consequently, Hypothesis 7 was supported. The interaction effect is displayed in Figure 3.

Results for day-level compensatory effort at work are displayed in Table 5. Model 1 showed a significant improvement over the null model $(\Delta-2 \times \log =19.965, \Delta \mathrm{df}=4, p<.001)$ and the general level of compensatory effort at work was a positive predictor of day-level compensatory effort at work. Model 2 showed no improvement over Model $1(\Delta-2 \times \log =7.523, \Delta \mathrm{df}=3$, ns $)$, and none of the estimates of the day-level stressors reached statistical significance. Model 3 showed an additional improvement over Model $2(\Delta-2 \times \log =10.915, \Delta \mathrm{df}=1, p<.001)$ and the state of being recovered in the morning was found to be a significant negative predictor of day-level compensatory effort at work. Therefore, Hypothesis 4 was confirmed. 
82

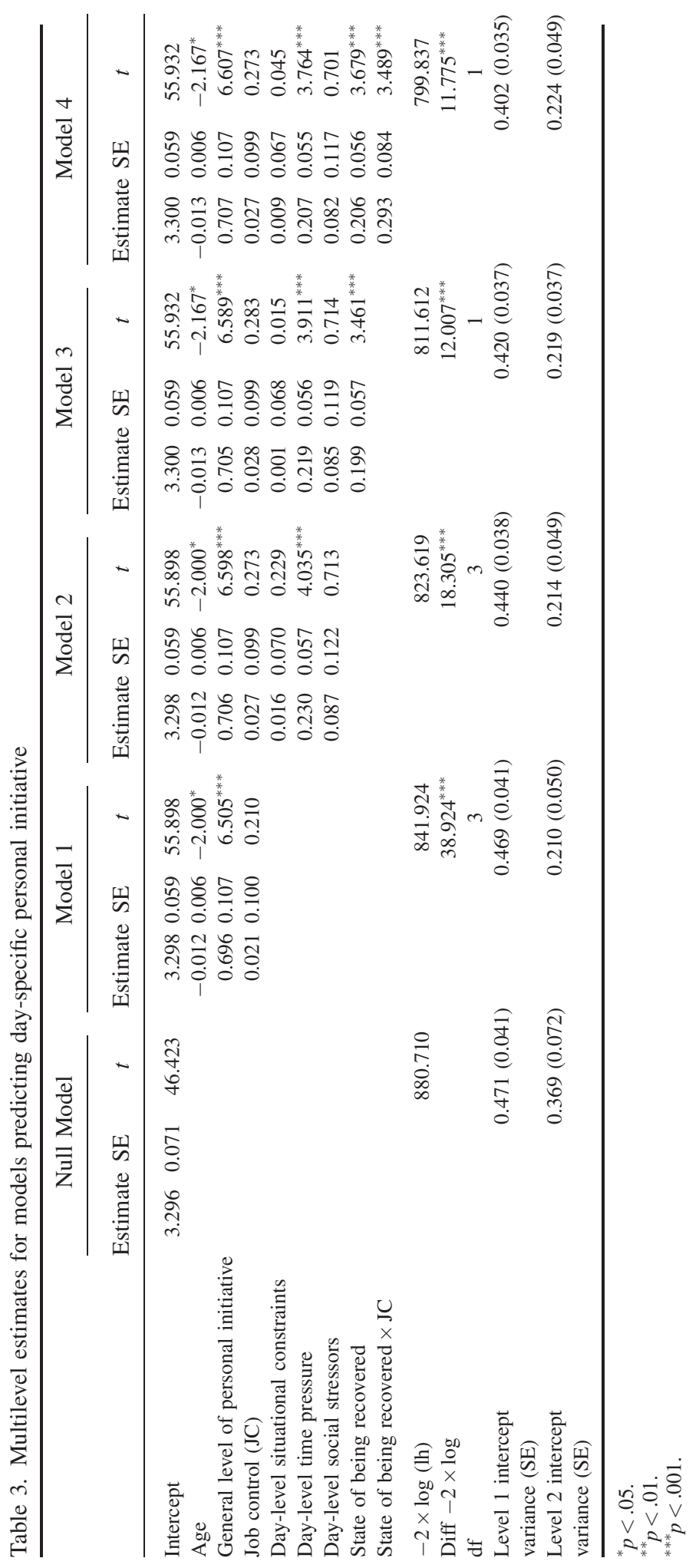




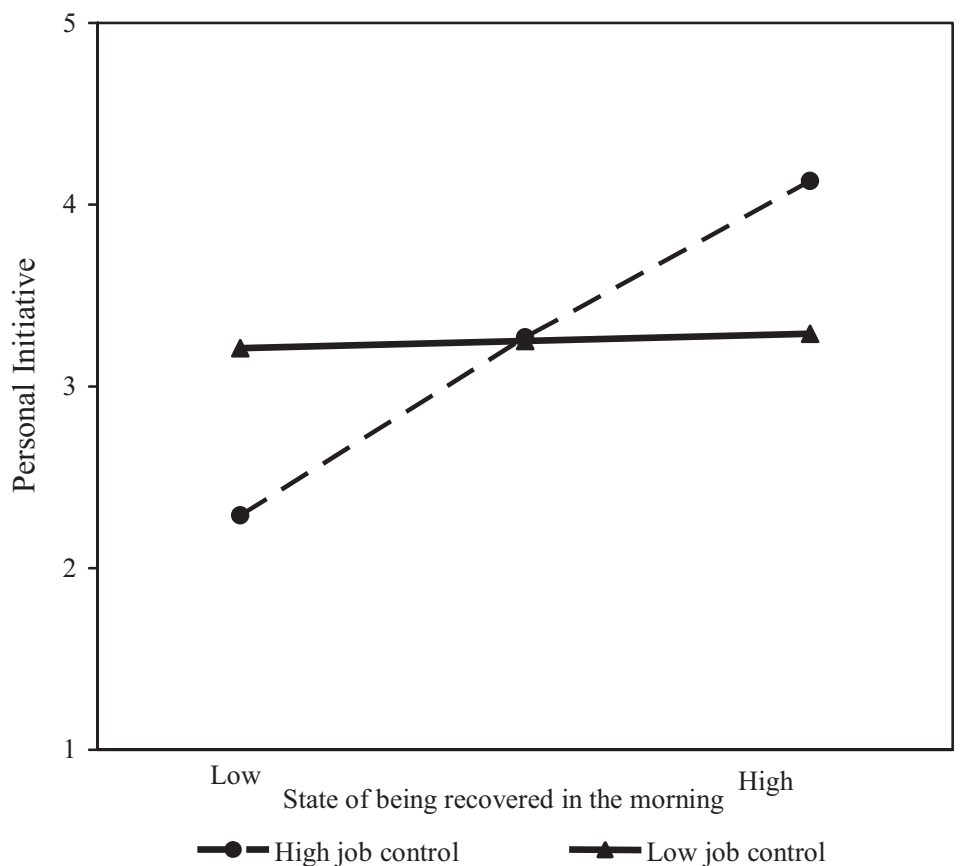

Figure 2. The interaction effect of the state of being recovered in the morning and job control on personal initiative

\section{Discussion}

The goal of the present study was to examine the relationship between the state of being recovered in the morning and different dimensions of job performance. Specifically, we looked at task performance, PI, OCB, and compensatory effort at work. Moreover, we investigated if situational strength (i.e., job control) served as a moderator in the relationships with task performance, PI, and OCB. All our hypotheses were supported. The state of being recovered in the morning was positively related to daily job performance and was negatively related to daily compensatory effort at work. Job control was a boundary condition in the relationship between the state of being recovered and daily task performance, PI, and OCB, as it moderated these relationships. For individuals with high job control, there was a strong positive relationship between being recovered in the morning and daily job performance, whereas there was no relationship for individuals with low job control.

Considering our results, it is important to note that the state of being recovered in the morning predicted performance variables beyond control variables from the person-level, specifically the general level of the respective performance variable and age, and beyond day-level control variables, specifically daily stressors. Thus, our results cannot be explained by between-person differences in age, general level of job performance, or by the perception of stress during the day.

Notwithstanding, our control variables as daily job stressors showed an interesting pattern of relationships with daily job performance. Day-level time pressure was positively related to daily task performance and PI, whereas day-level social stressors were positively related to daily OCB. A positive relationship between time pressure and PI was also found in previous studies (Fay \& Sonnentag, 2002; Ohly, Sonnentag, \& Pluntke, 2006). Fay and Sonnentag (2002) suggested control theory (Edwards, 


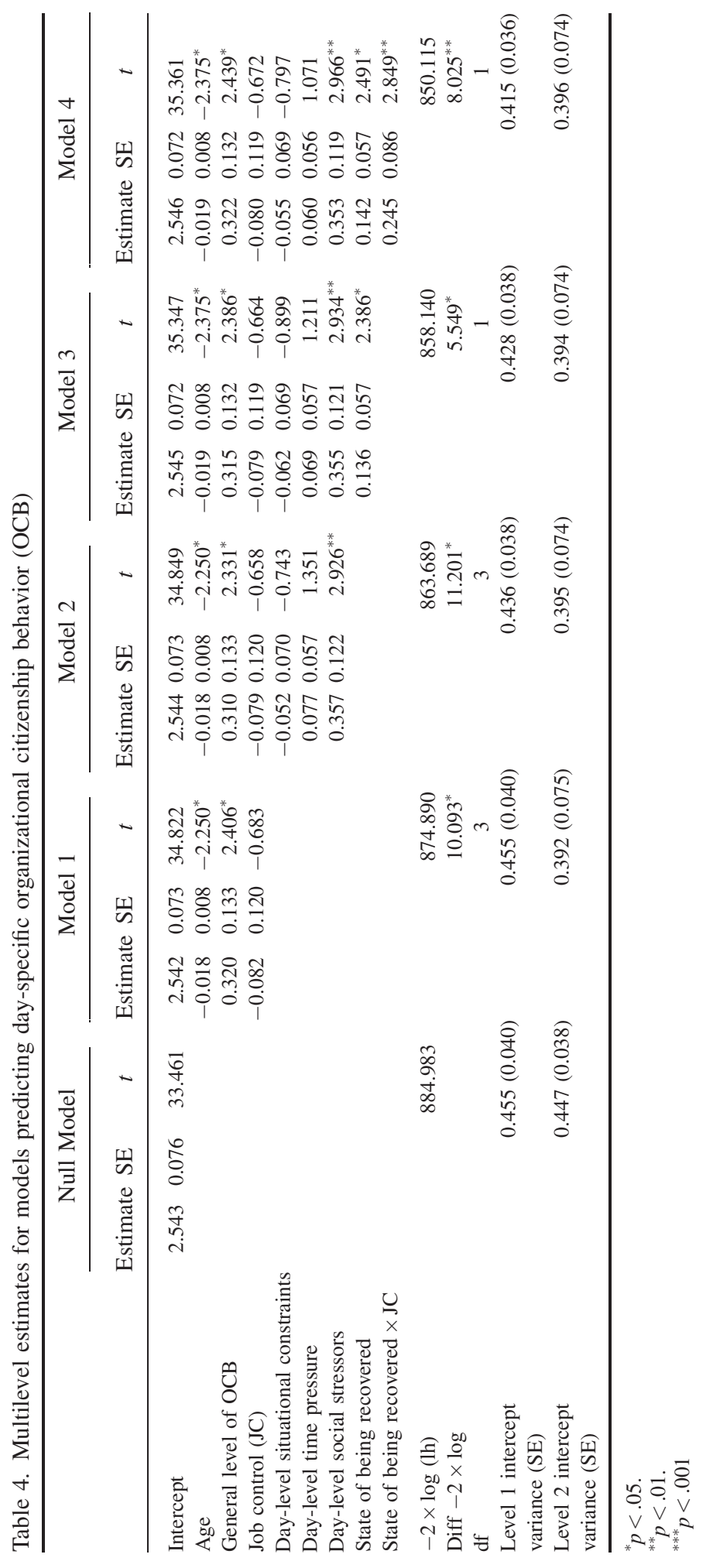




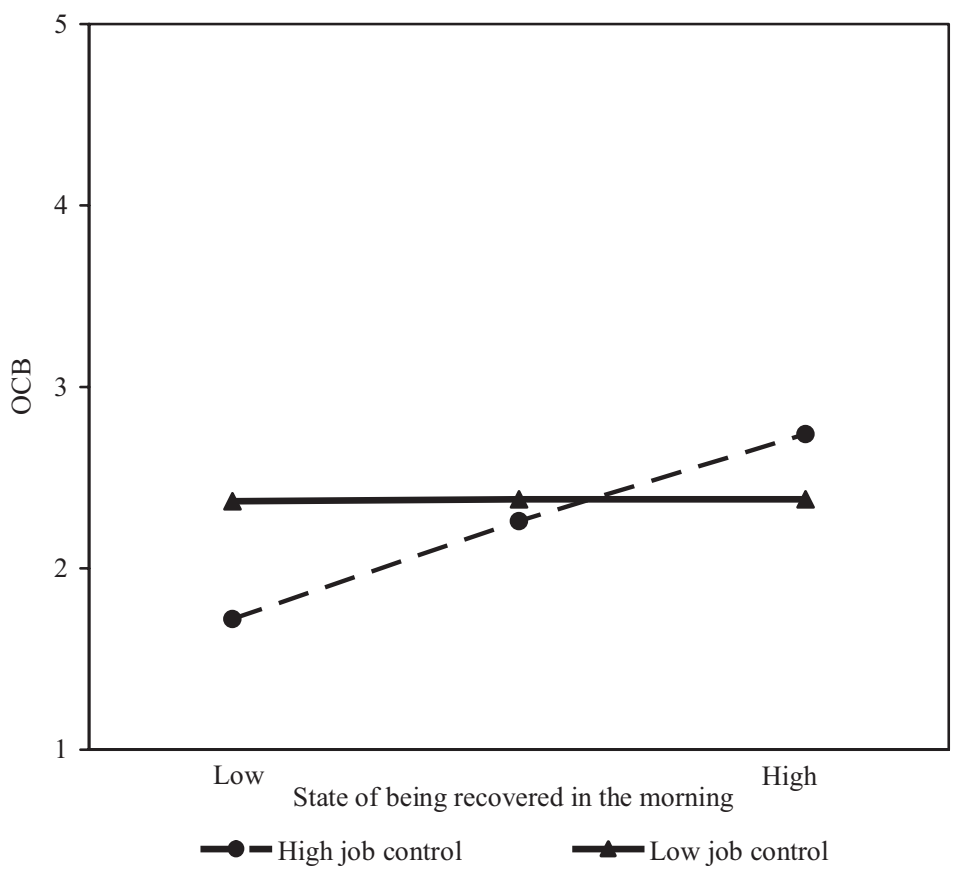

Figure 3. The interaction effect of the state of being recovered in the morning and job control on organizational citizenship behavior

1992) to explain this relationship. Stressors can be seen as indicators of suboptimal work situations that have to be changed. As a consequence, they trigger behaviors that counteract these suboptimal work situations. An increased level of task performance and PI involves finishing tasks and solving problems. Thus, an increased level of day-level task performance and PI may aim to reduce time pressure. An increased level of day-level OCB may aim to reduce social stressors, because helping behavior involves ameliorating conflicts in the workplace and improving the working climate. However, as we measured day-level stressors and day-specific performance at the same time, causal relationships remain unclear. It is also possible that an increased level of PI may result into a higher level of time pressure, because a person engages in extra activities that may be time consuming and therefore time for completing formal job tasks is reduced. Future studies should clarify the causal relationships between stressors and job performance using experimental study designs.

Our study contributes to theory on dynamic performance, as we identified changes in the state of being recovered as a predictor of changes in daily job performance. Because daily job performance depends on successfully allocating the maximum amount of resources to the task at hand (Beal et al., 2005), our results suggest that being highly recovered in the morning is associated with an increased amount of resources that promotes this process of resource allocation. Particularly, this enhancement may be due to increased self-regulatory resources that have been built up during the previous recovery period. The dynamic performance of Beal et al. (2005) refers to task performance. Our results indicate that the basic principles may also be applied to the dynamics of contextual performance. The state of being recovered, that is, having one's resources successfully replenished, positively predicted daily fluctuations in task performance and in contextual performance. The study of Trougakos et al. (2008) found similar results showing that recovery during breaks is positively related to subsequent performance. These findings indicate that it is promising to integrate recovery processes and 


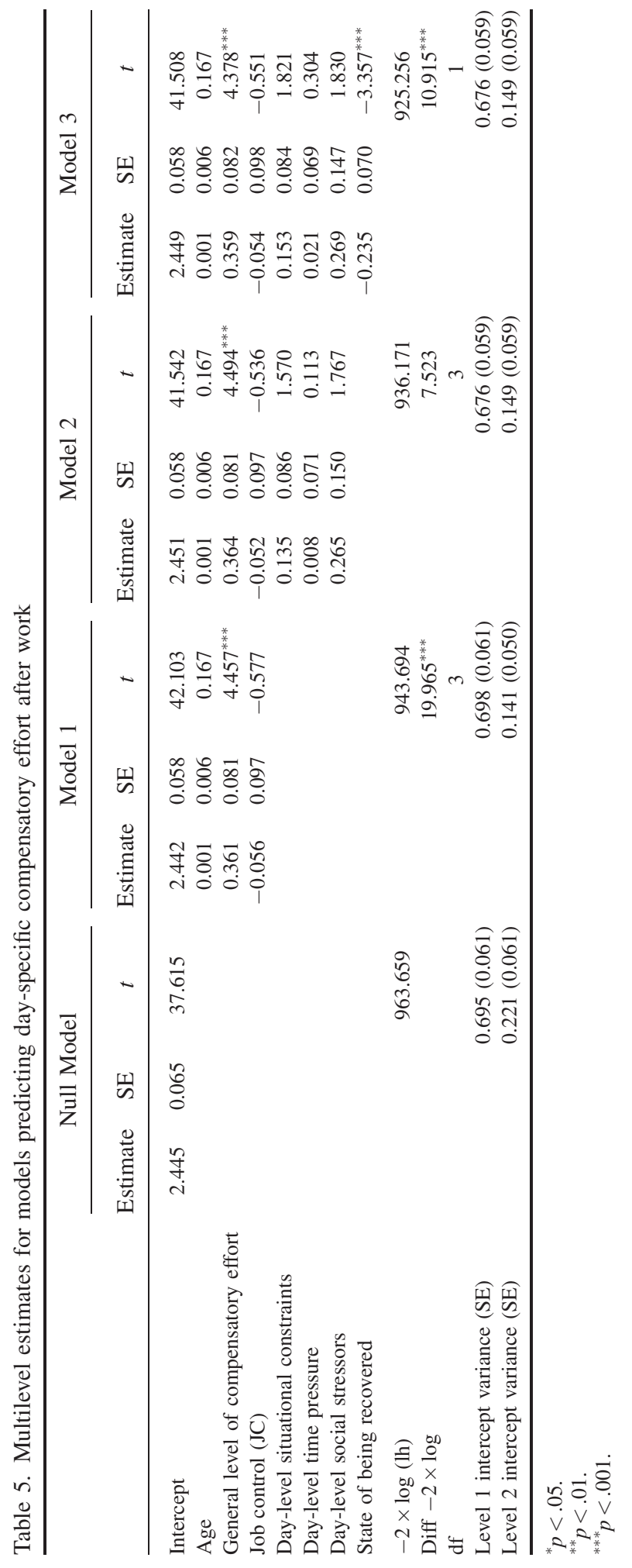


specifically processes of resource replenishment into models of dynamic performance (cf. Trougakos et al., 2008).

In addition, feeling recovered in the morning is associated with less compensatory effort during the day. Performance is easier to accomplish when a person feels highly recovered. Thus, it is not only the performance itself that benefits from an increased state of being recovered, but also the psychological costs of performing at work. Again, this finding supports the view that the state of being recovered is associated with increased self-regulatory resources that facilitate resource allocation and help keeping attention to the task (Beal et al., 2005). Performing one's tasks with less psychological costs should be important for showing high performance over a longer period of time and for avoiding the costs of a sustained high-effort investment, such as fatigue and failures at work (Hockey, 1997; Hockey et al., 1998).

Moreover, our results extended previous research on performance-related outcomes of recovery processes. We extended the results from a within-person study that showed that daily recovery is positively related to day-level proactive behavior (Sonnentag, 2003). We found that being highly recovered in the morning is also related to increased task performance and helping behavior during the day. Therefore, we showed that recovery is not only related to one single aspect of performance, but also to a broad range of performance behaviors. As we found a positive relationship between being recovered and $\mathrm{OCB}$, we extended previous findings showing that individuals do not only improve their own performance when being highly recovered, but also help their coworkers, what probably has additional organizational benefits.

Our study also contributed to theoretical considerations with regard to recovery and performance because we identified job control as a boundary condition in the relationship between daily recovery and performance. As predicted, the relationships between the state of being recovered and task performance, PI, and OCB were moderated by job control - an indicator of situational strength at work. On days when being highly recovered, an individual with high job control showed a higher level of task performance, PI, and OCB, whereas on days when being poorly recovered, an individual with high job control showed a lower level of task performance, PI, and OCB. For individuals with low job control, we found no relationship between the state of being recovered and job performance. These findings support our proposition that low job control constrains individuals in their possibilities to capitalize on being highly recovered. Because low job control limits an individual's actions and action strategies (Langfred \& Moye, 2004), the individual cannot increase job performance when being highly recovered, but also cannot decrease performance when being poorly recovered. A high level of job control enables individuals to bring in increased resources on days when they are highly recovered and thus allows for a rise in daily job performance. However, a high level of job control also allows individuals to decrease daily performance on days when they are poorly recovered. Reducing performance on days when an individual is less recovered may be a coping strategy to conserve resources and prevent a further resource loss (Hobfoll, 1989). In the short run, performance may suffer on that specific day, but in the long run conserving one's resources on such a day might be supportive for upholding performance over a longer period of time.

One substantial limitation of many previous diary studies was that one could not be sure if participants answered daily surveys at the right times (i.e., because participants filled out paper surveys and sent them back later). This study overcame this problem by implementing daily surveys on pocket computers that recorded the time of filling in surveys. All survey data that were filled in at wrong times were excluded from analyses.

\section{Limitations}

Our study has several limitations. First, we assessed daily performance by self-report measures. One might argue that these measures are biased in terms of social desirability or self-serving bias. However, 
we tried to rule out this explanation by our study design and by specific procedures in our data analyses. If participants' answers were biased, questionnaire and daily survey data should be influenced equally by such biases. Biases should influence the absolute level of performance and should be attributable between-person variation and not within-person variation. In our analyses, we centered day-level variables around the respective person mean. By this procedure between-person variance is eliminated from day-level predictor variables and interpretations based on differences between persons can be ruled out. Furthermore, we controlled for the general level of performance variables or compensatory effort at work in order to control for between-person influences such as self-serving bias.

Second, all of our measures are based on self-reports of the same person and thus common method variance might be a problem (Podsakoff, MacKenzie, Jeong-Yeon, \& Podsakoff, 2003). We tried to minimize this problem by temporally and methodologically separating the measurement of our predictor and outcome variables. Such a procedure should reduce common method variance (Podsakoff et al., 2003). Nevertheless, future studies should try to assess supervisor and peer ratings of performance or collect objective performance data. However, it is not certain if supervisors or peers are able to observe, notice, and evaluate changes in performance from day to day. Thus, it is unclear if such ratings are more valid than self-reports because they might also be susceptible to biases. As researchers begin to examine dynamic performance over short periods of time, future studies should also address these methodological problems and challenges.

In addition, our sample included German and Swiss participants. It may be possible that cross-cultural differences resulted into different interpretations of some items by German and Swiss participants. As our Swiss sample was very small (i.e., six participants including 21 days), we could not test for scale equivalence in the two subsamples. However, future studies should pay attention to such cross-cultural differences and test if such differences are responsible for low reliabilities of some daily measures as found in our study. ${ }^{2}$

A further limitation is that the assessment of feeling recovered in the morning might have increased participants' attention to their state of being recovered. ${ }^{3}$ Participants might have been worried or happy about this state during the day and thus daily performance might have been impacted. Future research should clarify if the relationship between the state of being recovered and daily performance depends on individuals' awareness of being recovered.

Moreover, with our study design we cannot ultimately draw conclusions about the causal relationships between the state of being recovered and daily performance. Although our design and data-analysis should have ruled out many alternative explanations (e.g., between-person third variables and certain day-level variables as confounding variables), we cannot conclude that the state of being recovered caused daily job performance. Future studies with experimental designs are needed to draw conclusions about causality.

Furthermore, although our results support the view that the state of being recovered in the morning is associated with a higher level of resources (e.g., self-regulatory resources) and that these resources contribute to increases in daily performance, we did not test this assumption. Examining which resources are increased by daily recovery and which resources mediate the relationship between the state of being recovered and daily performance is a major task for future research. In our study, we did not test for potential mediators for two reasons. First, as research on the relationship between recovery and performance is relatively scarce, the aim of our study was to examine if there is a stable relationship between the state of being recovered and performance. An established relationship between two variables is the basis for assuming and testing mediators (Shrout \& Bolger, 2002). Second, we think that it seems more promising to investigate and measure potential mediators in an experimental design than

\footnotetext{
${ }^{2} \mathrm{We}$ are indebted to an anonymous reviewer for pointing out this problem.

${ }^{3}$ We thank an anonymous reviewer for referring to this limitation.
} 
in a field study. For example, the assessment of self-regulatory resources may be difficult in a field study, whereas assessment methods in experiments have been developed (Baumeister, 2002).

\section{Implications for research and practice}

One area for future research is to investigate the processes at work that are facilitated or impaired when an individual is highly or poorly recovered, that is, examining performance from a micro perspective. The state of being recovered might be related to regulatory processes, such as goal regulation, including behaviors of planning or feedback processing. Such regulatory processes might mediate the effects of the state of being recovered on performance.

In addition to examining micro processes, research should also investigate the effects of the state of being recovered on performance over longer periods of time and the effects of cumulative lack of recovery. This topic is of particular importance because it might be that the effects and adjustment strategies associated with the state of being recovered improve performance in the short run, but may deteriorate performance in the long run. For example, persons at a workplace with a low degree of job control show a constant level of day-specific performance irrespective of their state of being recovered. However, if the state of being poorly recovered persists over time, performance might also decrease.

With respect to practical implications, this study illustrates that individuals and organizations should care about individuals' recovery. The state of being recovered can no longer be assumed to be a state that matters only for the non-work domain or with respect to health-related outcomes. Rather, it is a state that is related to day-specific task performance, day-specific contextual performance, and to the psychological costs of performance. If organizations support employees' opportunities to recover (e.g., by providing sport facilities or by offering working time arrangements that allow and promote day-specific recovery), organizations can directly increase employees' state of being recovered and indirectly foster employees' performance. Thus, the effectiveness of the whole organization would likely improve. Previous research showed that specific activities (Sonnentag, 2001) or experiences (Sonnentag \& Fritz, 2007) during leisure time are beneficial for employees' recovery and health. Furthermore, support in the non-work domain (e.g., social support from the family) should be important for employees' health and recovery (Halbesleben, 2006). In addition, developing and offering trainings that help individuals to identify their personal preferences and capabilities to recover from work-related stress may be an effective intervention to promote individuals' daily recovery.

Our results show that the state of being recovered is especially important for employees' daily job performance when job control is high. Increasing job control allows employees to capitalize on being highly recovered. However, increasing job control also enables employees to decrease performance when they are poorly recovered. Thus, managers and organizations should also take care of employees' recovery when providing employees with high job control.

Organizations can only provide recommendations, resources, and possibilities to foster the recovery process of their employees. How employees spend their leisure time is at their own decision and their own responsibility. Therefore, we should make people aware of the fact that the state of being recovered is related to performance at work and that they themselves have the possibility to positively influence daily performance at work.

In sum, our study demonstrates that the state of being recovered in the morning is important to ensure daily performance at work. One should not delay recovery by waiting for the weekend because the effects of being poorly recovered on performance occur immediately. Employees should be encouraged to maintain or develop a lifestyle that allows for daily periods of rest and recovery. The state of being recovered is not only a pleasant experience for the individual but it is also crucial for daily job performance in an organizational context. 


\section{Acknowledgements}

This study is part of Carmen Binnewies' dissertation and was funded by a grant from the German Research Foundation (DFG; SO 295/4-1, 4-2), which is gratefully acknowledged. Parts of this study were presented at the 2006 International Congress of Applied Psychology in Athens, Greece and at the 2006 Academy of Management Meeting in Atlanta, GA. We are grateful to Claudius Bornemann, Julia Meyer-Schwickerath, Christian Peters, and Signe Seiler for their involvement in data collection and Katherine N. Alexander, Jana Kühnel, Sylvia Lindinger-Sternart, Jennifer A. McInroe, Claudia Niklas, Jennifer L. Sparr, Anne Spychala, Jennifer E. Yugo, as well as Neal Ashkanasy, and three anonymous reviewers for helpful comments on earlier versions of this manuscript.

\section{Author biographies}

Carmen Binnewies is a doctoral student in industrial and organizational psychology at the University of Konstanz, Germany. Her research interests include (1) creative and proactive behaviors at work, (2) recovery from work-related stress, and (3) processes of emotion and affect regulation at work. In her dissertation, she examined recovery from work-related stress and its relationships with different dimensions of job performance.

Sabine Sonnentag is a full professor of work and organizational psychology at the University of Konstanz, Germany. In her research she is mainly interested in how individuals can achieve sustained high performance at work and remain healthy at the same time. Her major research topics include (1) recovery and unwinding from work stress, (2) job performance and its relationship to selfregulatory processes, and (3) continuous learning and proactivity at work. Currently, she is the editor of Applied Psychology: An International Review.

Eva J. Mojza is a doctoral student in industrial and organizational psychology at the University of Konstanz, Germany. Her research interests include work-related stress, recovery from work-related stress, the role of volunteer work during leisure time for recovery experiences, and positive relationships between work and non-work experiences with a main focus on the interface between volunteer work and paid work.

\section{References}

Aiken, L. S., \& West, S. G. (1991). Multiple regression: Testing and interpreting interactions. Thousand Oaks, CA: Sage Publications, Inc.

Barrick, M. R., \& Mount, M. K. (1993). Autonomy as a moderator of the relationships between the Big Five personality dimensions and job performance. Journal of Applied Psychology, 78, 111-118.

Baumeister, R. F. (2002). Ego depletion and self-control failure: An energy model of the self's executive function. Self and Identity, 1, 129-136.

Baumeister, R. F., Muraven, M., \& Tice, D. M. (2000). Ego depletion: A resource model of volition, selfregulation, and controlled processing. Social Cognition, 18, 130-150.

Beal, D. J., Weiss, H. M., Barros, E., \& MacDermid, S. M. (2005). An episodic process model of affective influences on performance. Journal of Applied Psychology, 90, 1054-1068. 
Beaty, J. C., Jr., Cleveland, J. N., \& Murphy, K. R. (2001). The relation between personality and contextual performance in 'strong' versus 'weak' situations. Human Performance, 14, 125-148.

Bolger, N., Davis, A., \& Rafaeli, E. (2003). Diary methods: Capturing life as it is lived. Annual Review of Psychology, 54, 579-616.

Borman, W. C., \& Motowidlo, S. J. (1993). Expanding the criterion domain to include elements of contextual performance. In N. Schmitt, \& W. C. Borman (Eds.), Personnel selection in organizations (pp. 71-98). New York: Jossey-Bass.

Bryk, A. S., \& Raudenbush, S. W. (1992). Hierarchical linear models: Application and data analysis methods. Newbury Park, CA: Sage.

Campbell, J. P. (1990). Modeling the performance prediction problem in industrial and organizational psychology. In M. D. Dunnette, \& L. M. Hough (Eds.), Handbook of industrial and organizational psychology (Vol. 1, 2nd ed., pp. 687-732). Palo Alto, CA: Consulting Psychologists Press, Inc.

Craig, A., \& Cooper, R. E. (1992). Symptoms of acute and chronic fatigue. In A. P. Smith, \& D. M. Jones (Eds.), Handbook of human performance, Vol 3: State and trait (pp. 289-339). San Diego, CA: Academic Press, Inc.

Crant, J. M. (2000). Proactive behavior in organizations. Journal of Management, 26, 435-462.

Deadrick, D. L., Bennett, N., \& Russell, C. J. (1997). Using hierarchical linear modeling to examine dynamic performance criteria over time. Journal of Management, 23, 745-757.

Eden, D. (2001). Vacations and other respites: Studying stress on and off the job. In C. L. Cooper, \& I. T. Robertson (Eds.), International review of industrial and organizational psychology (Vol. 16, pp. 121-146). New York: Wiley.

Edwards, J. R. (1992). A cybernetic theory of stress, coping, and well-being in organizations. Academy of Management Review, 17, 238-274.

Fay, D., \& Sonnentag, S. (2002). Rethinking the effects of stressors: A longitudinal study on personal initiative. Journal of Occupational Health Psychology, 7, 221-234.

Frese, M., Fay, D., Hilburger, T., Leng, K., \& Tag, A. (1997). The concept of personal initiative: Operationalization, reliability and validity of two German samples. Journal of Occupational and Organizational Psychology, 70, 139-161.

Frese, M., Kring, W., Soose, A., \& Zempel, J. (1996). Personal initiative at work: Differences between East and West Germany. Academy of Management Journal, 39, 37-63.

Frese, M., \& Zapf, D. (1987). Eine Skala zur Erfassung von sozialen Stressoren am Arbeitsplatz [A scale to assess social stressors in the workplace]. Zeitschrift für Arbeitswissenschaft, 41, 134-142.

Frese, M., \& Zapf, D. (1994). Action as the core of work psychology: A German approach. In H. C. Triandis, \& M. D. Dunnette, \& L. M. Hough (Eds.), Handbook of industrial and organizational psychology (Vol. 4, 2nd ed., pp. 271-340). Palo Alto, CA: Consulting Psychologists Press, Inc.

Fritz, C., \& Sonnentag, S. (2005). Recovery, health and job performance: Effects of weekend experiences. Journal of Occupational Health Psychology, 10, 187-199.

Ghiselli, E. E., \& Haire, M. (1960). The validation of selection tests in light of the dynamic nature of criteria. Personnel Psychology, 13, 225-231.

Halbesleben, J. R. B. (2006). Sources of social support and burnout: A meta-analytic test of the conservation of resources model. Journal of Applied Psychology, 91, 1134-1145.

Hobfoll, S. E. (1989). Conservation of resources: A new attempt at conceptualizing stress. American Psychologist, 44, 513-524.

Hobfoll, S. E. \& Shirom A. (Eds.), (2001). Conservation of resources theory: Applications to stress and management in the workplace. New York, NY: Marcel Dekker.

Hockey, G. R. J. (1993). Cognitive-energetical control mechanisms in the management of work demands and psychological health. In A. D. Baddeley, \& L. Weiskrantz (Eds.), Attention: Selection, awareness, and control: A tribute to Donald Broadbent (pp. 328-345). New York, NY: Clarendon Press/Oxford University Press.

Hockey, G. R. J. (1997). Compensatory control in the regulation of human performance under stress and high workload: A cognitive-energetical framework. Biological Psychology, 45, 73-93.

Hockey, G. R. J., Wastell, D. G., \& Sauer, J. (1998). Effects of sleep deprivation and user interface on complex performance: A multilevel analysis of compensatory control. Human Factors, 40, 233-253.

Hunter, J. E., \& Hunter, R. F. (1984). Validity and utility of alternative predictors of job performance. Psychological Bulletin, 96, 72-98.

Jackson, P. R., Wall, T. D., Martin, R., \& Davids, K. (1993). New measures of job control, cognitive demand, and production responsibility. Journal of Applied Psychology, 78, 753-762.

Kanfer, R., \& Ackerman, P. L. (2004). Aging, adult development, and work motivation. Academy of Management Review, 29, 440-458. 
Langfred, C. W., \& Moye, N. A. (2004). Effects of task autonomy on performance: An extended model considering motivational, informational, and structural mechanisms. Journal of Applied Psychology, 89, 934-945.

Lazarus, R. S., \& Folkman, S. (1984). Stress, appraisal, and coping. New York: Springer.

Locke, E. A., \& Latham, G. P. (1990). A theory of goal setting and task performance. Englewood Cliffs, NJ: Prentice-Hall.

Locke, E. A., \& Latham, G. P. (2004). What should we do about motivation theory? Six recommendations for the twenty-first century. Academy of Management Review, 29, 388-403.

Meijman, T. F., \& Mulder, G. (1998). Psychological aspects of workload. In P. J. D. Drenth, \& H. Thierry (Eds.), Handbook of work and organizational, Vol 2: Work psychology (2nd ed., pp. 5-33). Hove, England: Psychology Press/Erlbaum (UK) Taylor \& Francis.

Mischel, W. (1977). The interaction of person and situation. In D. Magnusson, \& N. S. Endler (Eds.), Personality at the crossroads: Current issues in interactional psychology (pp. 333-352). Hillsdale, NJ: Lawrence Erlbaum Associates, Inc.

Mojza, E. J., Peters, C., Sonnentag, S., \& Binnewies, C. (2007). Predictors of daily psychological detachment and mastery: The role of working hours, job stressors and working activities during leisure time. (submitted for publication).

Motowidlo, S. J., Borman, W. C., \& Schmit, M. J. (1997). A theory of individual differences in task and contextual performance. Human Performance, 10, 71-83.

Mount, M. K., \& Barrick, M. R. (1995). The Big Five personality dimensions: Implications for research and practice in human resources management. Research in Personnel and Human Resources Management, 13, $153-200$

Muraven, M., Baumeister, R. F., \& Tice, D. M. (1999). Longitudinal improvement of self-regulation through practice: Building self-control strength through repeated exercise. Journal of Social Psychology, 139, 446-457.

Ohly, S., Sonnentag, S., \& Pluntke, F. (2006). Routinization and its relationship with creative and proactive outcomes. Journal of Organizational Behavior, 27, 257-279.

Organ, D. W. (1994). Personality and organizational citizenship behavior. Journal of Management, 20, $465-478$.

Organ, D. W. (1997). Organizational citizenship behavior: It's construct clean-up time. Human Performance, 10, 85-97.

Parker, S. K., \& Wall, T. D. (1998). Job and work design: Organizing work to promote well-being and effectiveness. Thousand Oaks: Sage.

Podsakoff, P. M., MacKenzie, S. B., Jeong-Yeon, L., \& Podsakoff, N. P. (2003). Common method biases in behavioral research: A critical review of the literature and recommended remedies. Journal of Applied Psychology, 88, 879-903.

Podsakoff, P. M., MacKenzie, S. B., Paine, J. B., \& Bachrach, D. G. (2000). Organizational citizenship behaviors: A critical review of the theoretical and empirical literature and suggestions for future research. Journal of Management, 26, 513-563.

Rasbash, J., Browne, W., Goldstein, H., Yang, M., Plewis, I., Healy, M., et al. (2000). A. user's guide to MLwiN. London, UK: Institute of Education, University of London.

Roe, R. A., Zinovieva, I. L., Dienes, E., \& Horn, L. A. T. (2000). A. comparison of work motivation in Bulgaria, Hungary, and The Netherlands: Test of a model. Applied Psychology: An International Review, 49, 658-687.

Schmeichel, B. J., \& Baumeister, R. F. (2004). Self-regulatory strength. In R. F. Baumeister, \& K. D. Vohs (Eds.), Handbook of self-regulation: Research, theory, and applications (pp. 84-98). New York: Guilford Press.

Semmer, N. (1984). Streßbezogene Tätigkeitsanalyse [Stress-oriented analysis task-analysis]. Weinheim: Beltz. Semmer, N., Zapf, D., \& Dunckel, H. (1999). Instrument zur stressbezogenen Tätigkeitsanalyse (ISTA). In H. Dunckel (Ed.), Handbuch psychologischer Arbeitsanalyseverfahren (pp. 179-204). Zürich: vdf Hochschulverlag an der ETH.

Semmer, N., Zapf, D., \& Greif, S. (1996). 'Shared job strain': A new approach for assessing the validity of job stress measurements. Journal of Occupational and Organizational Psychology, 69, 293-310.

Shrout, P. E., \& Bolger, N. (2002). Mediation in experimental and nonexperimental studies: New procedures and recommendations. Psychological Methods, 7, 422-445.

Smith, C. A., Organ, D. W., \& Near, J. P. (1983). Organizational citizenship behavior: Its nature and antecedents. Journal of Applied Psychology, 68, 653-663.

Snijders, T. A. B., \& Bosker, R. J. (1999). Multilevel analysis. An introduction to basic and advanced multilevel modeling. London: Sage.

Sonnentag, S. (2001). Work, recovery activities, and individual well-being: A diary study. Journal of Occupational Health Psychology, 6, 196-210. 
Sonnentag, S. (2003). Recovery, work engagement, and proactive behavior: A new look at the interface between nonwork and work. Journal of Applied Psychology, 88, 518-528.

Sonnentag, S., Binnewies, C., \& Mojza, E. J. (2008) “Did you have a nice evening?” A day-level study on recovery experiences, sleep and affect. Journal of Applied Psychology, 93, 674-684.

Sonnentag, S., \& Fritz, C. (2007). The recovery experience questionnaire: Development and validation of a measure for assessing recuperation and unwinding from work. Journal of Occupational Health Psychology, 12, 204-221.

Sonnentag, S., \& Kruel, U. (2006). Psychological detachment from work during off-job time: The role of job stressors, job involvement, and recovery-related self-efficacy. European Journal of Work and Organizational Psychology, 15, 197-217.

Staufenbiel, T., \& Hartz, C. (2000). Organizational citizenship behavior: Entwicklung und erste Validierung eines Messinstruments [Organizational Citizenship Behavior: Development and validation of a measurement instrument]. Diagnostica, 46, 73-83.

Trougakos, J. P., Beal, D. J., Green, S. G., \& Weiss, H. M. (2008). Making the break count: An episodic examination of recovery activities, emotional experiences, and affective delivery. Academy of Management Journal, 51, 131-146.

Van Dyne, L., \& LePine, J. A. (1998). Helping and voice extra-role behaviors: Evidence of construct and predictive validity. Academy of Management Journal, 41, 108-119.

Williams, L. J., \& Anderson, S. E. (1991). Job satisfaction and organizational commitment as predictors of organizational citizenship and in-role behaviors. Journal of Management, 17, 601-617.

Zapf, D. (1993). Stress-oriented analysis of computerized office work. European Work and Organizational Psychologist, 3, 85-100.

Zijlstra, F., \& Cropley, M. (2006). Recovery after work. In F. Jones, R. J. Burke, \& M. Westman (Eds.), Work-life balance: A psychological perspective (pp. 219-234). New York, NY: Psychology Press. 